Supporting Information for

\title{
Computational Insights into As(V) Removal from Water by UiO-66 Metal- Organic Framework
}

\author{
Claudia S. Cox, ${ }^{\mathrm{a}}$ Valeria Cossich Galicia, ${ }^{\mathrm{b}}$ Martina Lessio ${ }^{\mathrm{a}}$ * \\ a School of Chemistry, University of New South Wales, Sydney, NSW 2052, Australia \\ ${ }^{\mathrm{b}}$ Columbia College, Columbia University, New York, 10027, USA \\ *martina.lessio@unsw.edu.au
}

Contents:

1) Explicit solvation and computed acidity constants

2) Vibrational frequency analysis and comparison to experimental data from the literature

3) $\mu 3-\mathrm{OH}$ displacement adsorption mode analysis

4) Steric considerations for $\mathrm{As}(\mathrm{V})$ distribution in UiO-66 pores and adsorption on neighboring defect sites

5) Co-adsorption of different pairs of $\mathrm{As}(\mathrm{V})$ species in double monodentate adsorption mode

6) References

7) Cartesian coordinates of structures used in this work

\section{Explicit solvation and computed acidity constants}

In order to improve our model of species in solution we introduced explicit water molecules. To systematically test the effect of including a varying number of explicit water molecules we computed the acidity constants $\left(\mathrm{p} K_{\mathrm{a}} \mathrm{s}\right)$ of relevant species with different numbers of water molecules. Their careful analysis and comparison to experimental values help us determine potential artificial biases in our model so that we can interpret our results more critically. The $\mathrm{p} K_{\mathrm{a}} \mathrm{s}$ were computed using the free energy of a solvated proton derived from empirical values described in numerous reports in the literature (see Ref. ${ }^{1}$ ) and the established equation:

$$
\mathrm{p} K_{\mathrm{a}}\left(\mathrm{XH}^{+}\right)=\Delta \mathrm{G} / 2.303 \mathrm{RT}
$$

where $\Delta \mathrm{G}$ is the reaction free energy in solution for the deprotonation of the generic protonated species $\mathrm{XH}^{+} . \Delta \mathrm{G}$ was calculated as described in the Theoretical Methods section of the main text. 
The computed $\mathrm{p} K_{\mathrm{a}}$ of water (Fig. S1) allows us to establish the extent to which we might be artificially biasing our computed reaction free energies for $\mathrm{As}(\mathrm{V})$ adsorption by protonating the displaced hydroxide ligand. A significantly higher $\mathrm{p} K_{\mathrm{a}}$ relative to the experimental value would suggest that we are introducing an artificial driving force for the arsenic binding reaction. If this was the case, the observed significantly more favourable reaction free energies (by $36.7 \mathrm{kcal} / \mathrm{mol}$ with no explicit water molecules and by $24.6 \mathrm{kcal} / \mathrm{mol}$ with three explicit water molecules) for this type of reaction relative to displacing the hydroxide ligand without protonating it would not be realistic (Fig. S2). This clearly applies to the $\mathrm{p} K_{\mathrm{a}}$ computed with no explicit water molecules (28.9), which is over $13 \mathrm{p} K_{\mathrm{a}}$ units higher than the experimental value (15.7). However, including even just one explicit water molecule to our model of solvated $\mathrm{OH}^{-}$improves our predicted $\mathrm{p} K_{\mathrm{a}}$ (20.9) by $8 \mathrm{p} K_{\mathrm{a}}$ units. Including three explicit waters leads to the best result with the computed $\mathrm{p} K_{\mathrm{a}}(18.1)$ only $2.4 \mathrm{p} K_{\mathrm{a}}$ units (about $3.3 \mathrm{kcal} / \mathrm{mol}$ ) higher than the experimental one. This result suggests that explicit solvation with three water molecules leads to great improvement and that the reaction free energies computed with the displaced hydroxide undergoing protonation are not artificially biased by a poor model of solvated $\mathrm{OH}^{-}$. For this reason, we chose to always model hydroxide protonation upon its displacement. We note that, as discussed in the main text, when calculating reaction free energies we used the Eigen cation to model a solvated proton acting as the proton source for the displaced hydroxide. Using our Eigen cation model instead of the free energy of a solvated proton derived from empirical values changed the $\mathrm{p} K_{\mathrm{a}}$ values in Fig. S1 by only $0.5 \mathrm{p} K_{\mathrm{a}}$ units. Therefore, the conclusions drawn above apply to all of our results obtained using the Eigen cation solvated proton model as well.

The computed $\mathrm{p} K_{\mathrm{a}}$ of $\mathrm{H}_{3} \mathrm{AsO}_{4}, \mathrm{H}_{2} \mathrm{AsO}_{4}^{-}$, and $\mathrm{HAsO}_{4}{ }^{2-}$ (Fig. S1) allow us to gain insight into how our model captures the relative stability of these species and their ability to act as a proton source in comparison to solvated protons in water. Inclusion of varying numbers of explicit waters has minimal effect on the computed $\mathrm{H}_{3} \mathrm{AsO}_{4} \mathrm{p} K_{\mathrm{a}}$, which is higher than the experimental value by 3.4-4.3 $\mathrm{p} K_{\mathrm{a}}$ units (depending on the number of explicit water molecules included). For the other arsenic species $\mathrm{H}_{2} \mathrm{AsO}_{4}{ }^{-}$and $\mathrm{HAsO}_{4}{ }^{2-}$, varying the number of explicit water molecules has a more significant effect on the computed $\mathrm{p} K_{\mathrm{a}}$. More importantly, the $\mathrm{p} K_{\mathrm{a}}$ increase relative to experimental value gets larger, even upon the inclusion of four explicit water molecules $\left(10.2 \mathrm{p} K_{\mathrm{a}}\right.$ units for $\mathrm{H}_{2} \mathrm{AsO}_{4}{ }^{-}$and 7.8 for $\mathrm{HAsO}_{4}{ }^{2}$ ). Overall, these results indicate a potential systematic error in our model description of negatively charged species, especially the divalent and trivalent anions. This could be explained by the fact that these anions might exist as ion pairs ${ }^{2}$ or that more explicit water molecules are required. This investigation is beyond the scope of this work. In fact, as we illustrate in the main text, our main focus is to identify the most favourable adsorption mode for each As(V) species rather than drawing accurate comparisons of reaction free energies across different $\mathrm{As}(\mathrm{V})$ species.

Overall in this work we decided to use three explicit water molecules to improve the description of species in solution. This number provides the best result for the water $\mathrm{p} K_{\mathrm{a}}$ and overall acceptable results for the arsenic species in comparison to other numbers of explicit water 
molecules. The only exception is $\mathrm{HAsO}_{4}{ }^{2-}$ for which four explicit water molecules provide an improvement of nearly $5 \mathrm{p} K_{\mathrm{a}}$ units relative to three water molecules. This highlights the nonsurprising fact that $\mathrm{AsO}_{4}{ }^{3-}$ can gain significant stabilization from explicit solvation.

Finally, $\mathrm{p} K_{\mathrm{a}} \mathrm{s}$ can help us shed light on another important aspect discussed in the main text: can arsenic species act as proton source for the protonation of the displaced hydroxide capping ligand or are solvated protons the only viable proton source? In a previous experimental report, enhanced performance at low $\mathrm{pH}$ was discovered and it was tentatively explained by hypothesizing that proton transfer from arsenic to the displaced ligand is a necessary step for adsorption to occur. Enhanced performance at low $\mathrm{pH}$ could then be explained by the fact that more protonated arsenic species such as $\mathrm{H}_{3} \mathrm{AsO}_{4}$ prevail at low $\mathrm{pH} .{ }^{3}$ In order to address this point, we can compare the computed $\mathrm{p} K_{\mathrm{a}}$ of the Eigen cation (0.5) that we use to model the solvated protons (-1.8 $\mathrm{p} K_{\mathrm{a}}$ experimental value) to the $\mathrm{p} K_{\mathrm{a}}$ of the arsenic species. Our computed $\mathrm{p} K_{\mathrm{a}}$ for the arsenic species (Fig. S1) are always higher than the $\mathrm{p} K_{\mathrm{a}}$ of the Eigen cation, a result consistent with experimental results and which suggests that solvated protons are a better proton source than any of the $\mathrm{As}(\mathrm{V})$ species. This observation appears to contradict results presented in the main text (Fig. 3 vs. Fig. 4 comparison) showing that deprotonation is thermodynamically favourable for $\mathrm{H}_{3} \mathrm{AsO}_{4}$ adsorbing in any adsorption mode and $\mathrm{H}_{2} \mathrm{AsO}_{4}{ }^{-}$adsorbing in tridentate mode. However, as discussed in the main text, these results are promptly explained by the computed $\mathrm{p} K_{\mathrm{a}} \mathrm{s}$ of these adsorbed $\mathrm{As}(\mathrm{V})$ species, which are all more negative than the $\mathrm{p} K_{\mathrm{a}}$ of a solvated proton. 


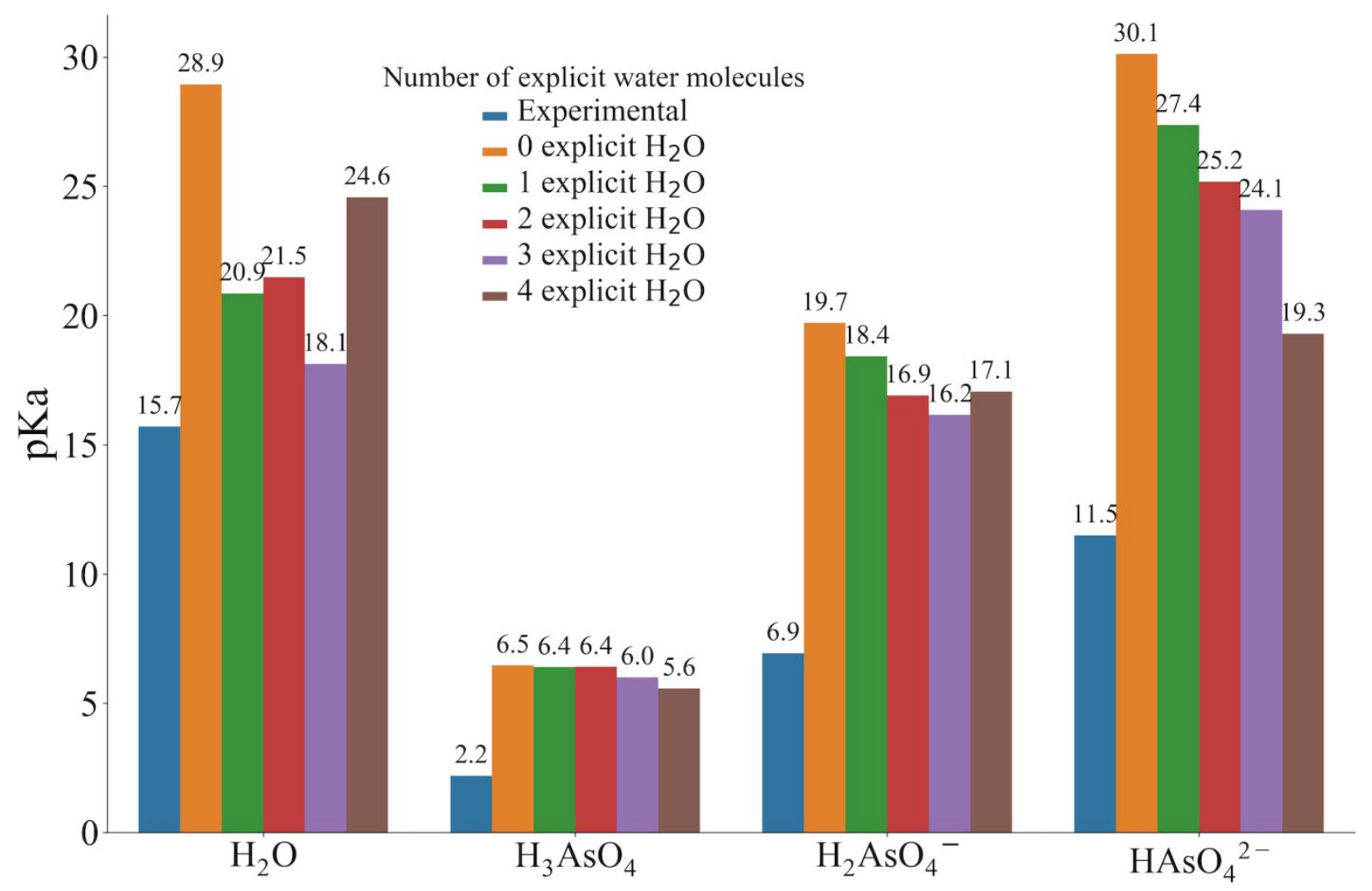

Figure S1. Effect of introducing different numbers of explicit water molecules (in addition to implicit solvation) on the computed acidity constants for water and As $(V)$ species. Note that in the case of the water $p K_{a}$ we modelled water using a nonamer cluster as this led to better agreement with the experimental $p K_{a}$ as opposed to using scaled water clusters of size consistent with the number of waters used to explicitly solvate $\mathrm{OH}^{-}$. 


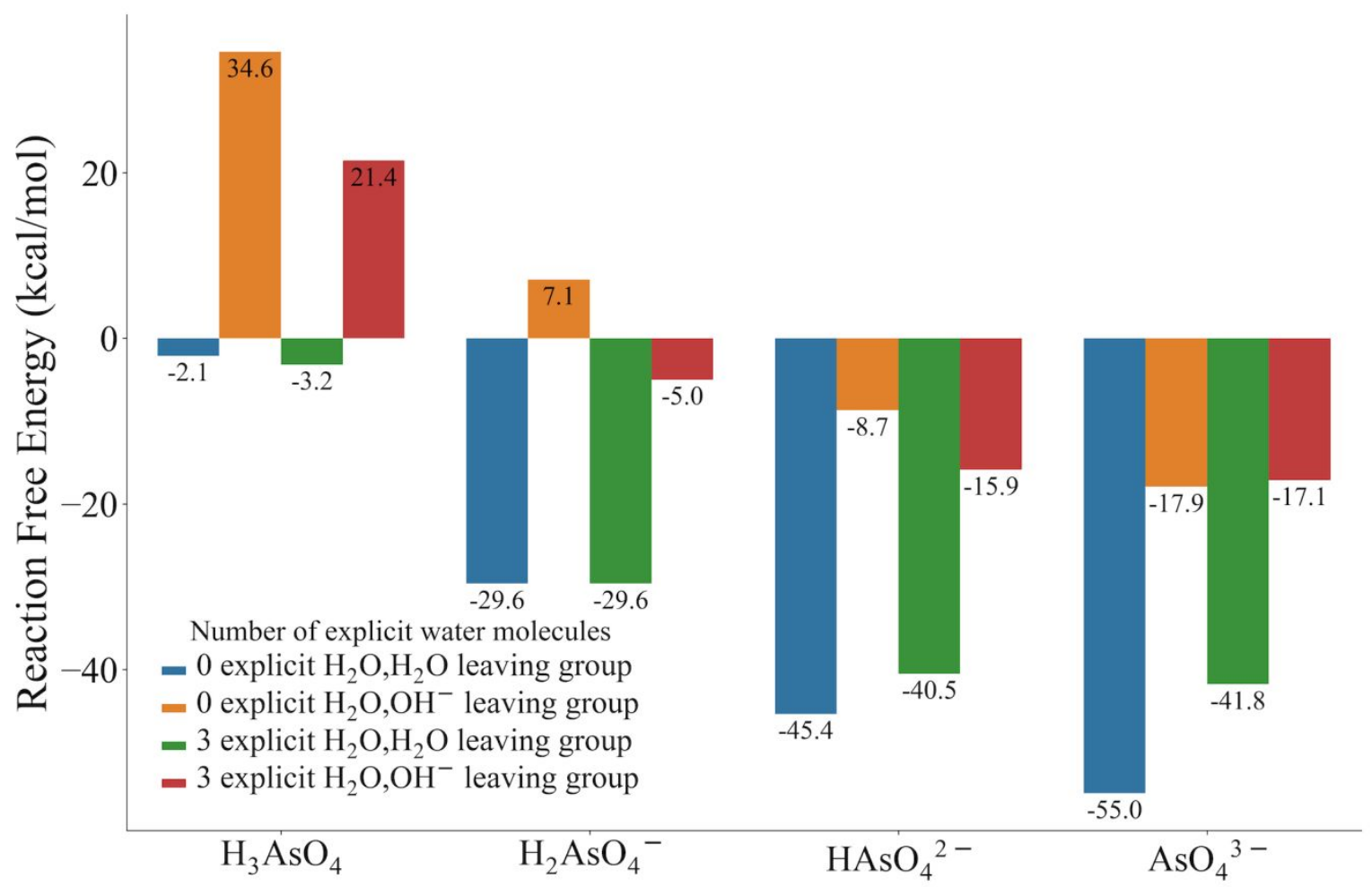

Figure S2. A comparison of the reaction free energies for As $(V)$ species binding in the bidentate configuration without undergoing deprotonation across changes in solvation model (implicit solvation only vs. mixed implicit-explicit solvation with three water molecules) and fate of $\mathrm{OH}^{-}$ upon displacement (gets protonated by a solvated proton and forms $\mathrm{H}_{2} \mathrm{O}$ in solution vs. remains deprotonated in solution). Reaction free energies are calculated relative to the [UiO-66]-OH-/ $\mathrm{H}_{2} \mathrm{O}$ defect site.

\section{Vibrational frequency analysis and comparison to experimental data from the literature}

Infrared (IR) spectra have been used in previous experimental studies to investigate the binding mode of $\mathrm{As}(\mathrm{V})$ species on $\mathrm{UiO}-66 .^{3-5}$ In Table S1 we present our computed vibrational frequencies for selected vibrational modes of relevance to the vibrational frequency assignments proposed in previous experimental studies. 
Table S1 Computed vibrational frequencies for selected vibrational modes of the [UiO-66]-OH$/ \mathrm{H}_{2} \mathrm{O}$ defect site (represented in Fig. le of the main text), pristine UiO-66 (represented in Fig. Ia of the main text) and the double monodentate adsorption mode for $\mathrm{H}_{2} \mathrm{AsO}_{4}{ }^{-} / \mathrm{H}_{2} \mathrm{As} \mathrm{O}_{4}$ (represented in Table 1 of the main text). A scaling factor of 0.9524 was applied from Ref. ${ }^{6}$ to correct for the overestimation of vibrational frequencies by density functional theory calculations. The atoms involved in the stretching vibration are indicated in brackets where necessary. The frequencies are reported in units of $\mathrm{cm}^{-1}$.

\begin{tabular}{|c|c|c|c|}
\hline Vibrational Mode & {$[\mathrm{UiO}-66]-\mathrm{OH} / \mathrm{H}_{2} \mathrm{O}$} & Pristine UiO-66 & $\begin{array}{l}\text { Double } \\
\text { monodentate } \\
\mathrm{H}_{2} \mathrm{AsO}_{4}^{-/} / \mathrm{H}_{2} \mathrm{AsO}_{4}\end{array}$ \\
\hline $\begin{array}{l}\mu 3-\mathrm{OH} \text { bending } \\
\text { mode }\end{array}$ & $713,754,782$ & $\begin{array}{l}685,710,741,773, \\
843\end{array}$ & 1005 \\
\hline $\begin{array}{l}\mu 3-\mathrm{OH} \text { stretching } \\
\text { mode }\end{array}$ & 3764 & 3768 & 3016 \\
\hline $\begin{array}{l}\text { Surface hydroxyl } \\
\text { bending mode }\end{array}$ & $\begin{array}{l}392 \text { (wagging) } \\
652 \text { (twisting) } \\
1212 \text { (rocking) } \\
1554 \text { (scissoring) }\end{array}$ & - & - \\
\hline $\begin{array}{l}\text { Surface hydroxyl } \\
\text { stretching mode }\end{array}$ & $2255,3719,3725$ & - & - \\
\hline $\begin{array}{l}\text { Zr-(O-As) } \\
\text { stretching mode }\end{array}$ & - & - & 862,881 \\
\hline $\begin{array}{l}\text { As- }(\mathrm{O}-\mathrm{H}) \\
\text { stretching mode }\end{array}$ & - & - & 3625,3680 \\
\hline
\end{tabular}

We analysed closely the vibrational frequencies associated with the $\mu 3-\mathrm{OH}$ bending mode. Wang et al. used the disappearance of spectral features assigned to this bending mode (namely the peak at $1055 \mathrm{~cm}^{-1}$ ) upon exposure of UiO-66 to water containing $\mathrm{As}(\mathrm{V})$ as evidence for their proposed $\mu 3-\mathrm{OH}$ displacement binding mode. ${ }^{3}$ Our computed vibrational frequencies for the $\mu 3-$ $\mathrm{OH}$ bending mode for pristine and defective UiO-66 are in the $680-850 \mathrm{~cm}^{-1}$ range and are in agreement with previous experimental and computational studies. ${ }^{78}$ This result is in contrast to the assignment of the $\mu 3-\mathrm{OH}$ bending mode to the peak at $1055 \mathrm{~cm}^{-1}$ proposed by Wang et al. ${ }^{3}$ This disagreement may be explained by the fact that Wang et al. assigned the peak based on previous experimental work on a different material, specifically amorphous zirconium oxide. ${ }^{9}$ Furthermore, the $700-800 \mathrm{~cm}^{-1}$ region in the experimental IR spectra reported by Wang et al. is mostly unchanged by $\mathrm{As}(\mathrm{V})$ adsorption, which suggests that $\mu 3-\mathrm{OH}$ displacement is not occurring in contrast to their proposal. 
Following this conclusion the question remains of what is the vibrational mode associated with the disappearing peak at $1055 \mathrm{~cm}^{-1}$. One possible explanation is that this peak corresponds to the $\mu 3-\mathrm{OH}$ group hydrogen bonded to water. Such hydrogen bonds are expected to cause a blue shift of the bending mode frequencies ${ }^{10}$ and this is also confirmed by our computed vibrational frequencies $\left(1037 \mathrm{~cm}^{-1}\right.$ computed vibrational frequency for the bending mode of the $\mu 3-\mathrm{OH}$ group with a water molecule hydrogen-bonded to it). However, hydrogen bonded water is unlikely to be present if the sample was dried at high temperature as described by Wang et al. An alternative explanation is that the $1055 \mathrm{~cm}^{-1}$ peak corresponds to the $\mathrm{H}-\mathrm{C}-\mathrm{O}$ bending mode of formate capping ligands (1035 $\mathrm{cm}^{-1}$ computed vibrational frequency), which may be present in place of the 1,4benzenedicarboxylic acid (BDC) linker due to the use of dimethylformamide in the synthesis of UiO-66. As discussed in the main text (Fig. 5), displacement reactions involving formate capping ligands are the most thermodynamically favourable among the different monocarboxylic acids considered in this work. It is therefore possible that these capping ligands are present and get displaced upon the adsorption of $\mathrm{As}(\mathrm{V})$ species, causing the peak at $1055 \mathrm{~cm}^{-1}$ to disappear. Finally, we also explored the possibility that this peak may be associated with the bending vibration of the $\mathrm{Zr}-\mathrm{O}-\mathrm{H}$ groups in the [UiO-66]-OH$/ / \mathrm{H}_{2} \mathrm{O}$ defect site, which is the main type of defect site investigated in this work. The adsorption of $\mathrm{As}(\mathrm{V})$ species would cause the displacement of $\mathrm{OH}^{-}$ and $\mathrm{H}_{2} \mathrm{O}$ capping ligands and hence the disappearance of IR features associated with their vibrational modes. However, as demonstrated by the frequency values reported in Table S1, bending modes involving the capping ligands have significantly different frequencies from the experimentally observed peak at $1055 \mathrm{~cm}^{-1}$.

Previous studies used peaks in the $810-890 \mathrm{~cm}^{-1}$ region assigned to $\mathrm{Zr}-(\mathrm{O}-\mathrm{As})$ bond stretching as evidence for the adsorption of $\mathrm{As}(\mathrm{V})$ species via the formation of $\mathrm{Zr}$-O-As covalent bonds. ${ }^{4,5,11}$ Our computed vibrational frequencies of this vibrational mode for the $\mathrm{H}_{2} \mathrm{AsO}_{4}{ }^{-} / \mathrm{H}_{2} \mathrm{AsO}_{4}{ }^{-}$double monodentate adsorption mode $\left(862 \mathrm{~cm}^{-1}\right.$ and $881 \mathrm{~cm}^{-1}$ for the $\mathrm{Zr}-(\mathrm{O}-\mathrm{As})$ bond stretch) are consistent with this assignment. Furthermore, our computed frequencies for the $\mathrm{As}(\mathrm{O}-\mathrm{H})$ stretching mode at 3625 and $3680 \mathrm{~cm}^{-1}$ are in agreement with the assignment of the experimental peak at $3654 \mathrm{~cm}^{-1}$ proposed in the experimental work by Audu et al. ${ }^{4}$

\section{$3 \quad \mu 3-O H$ displacement adsorption mode analysis}

In the main text (Table $\mathrm{S} 2$ and related discussion) we showed that the $\mu 3-\mathrm{OH}$ displacement adsorption mode is highly unstable for $\mathrm{H}_{2} \mathrm{AsO}_{4}{ }^{-}(\Delta \mathrm{G}=+12.9 \mathrm{kcal} / \mathrm{mol})$ and hence we decided to dismiss it when we expanded our analysis to other $\mathrm{As}(\mathrm{V})$ species. For the sake of completeness, here we show that this adsorption mode remains unfavourable for other $\mathrm{As}(\mathrm{V})$ species $\left(\mathrm{H}_{3} \mathrm{AsO}_{4}\right.$ and $\mathrm{HAsO}_{4}{ }^{2}$ ) and for different types of binding sites (pristine UiO-66 and [UiO-66]-OH- $/ \mathrm{H}_{2} \mathrm{O}$ ). The results of this analysis are reported in Table $\mathrm{S} 2$ and show that reaction free energies for the $\mu 3-\mathrm{OH}$ displacement adsorption mode are unfavourable in all cases. We observe that the [UiO66]-OH- $/ \mathrm{H}_{2} \mathrm{O}$ binding site is preferred over pristine UiO-66 by nearly $10 \mathrm{kcal} / \mathrm{mol}$ in the case of $\mathrm{H}_{2} \mathrm{AsO}_{4}{ }^{-}$due to the formation of multiple hydrogen bonds between $\mathrm{H}_{2} \mathrm{AsO}_{4}{ }^{-}$and the capping ligands. However, as already shown in the main text, such interactions do not provide enough 
stabilization for the $\mu 3-\mathrm{OH}$ displacement adsorption mode to be favourable for $\mathrm{H}_{2} \mathrm{AsO}_{4}^{-}$. Note that no results for $\mathrm{AsO}_{4}{ }^{3-}$ binding via $\mu 3-\mathrm{OH}$ displacement are reported due to this mode proving unstable upon geometry optimization (i.e., the ( $\mu 3-\mathrm{O})$-As bond spontaneously broke resulting in $\mathrm{AsO}_{3}$ formation).

Table S2. Reaction free energies for $\mathrm{As}(\mathrm{V})$ species to bind via $\mu 3-\mathrm{OH}$ displacement on pristine $\mathrm{UiO}-66$ and at the [UiO-66]-OH- $/ \mathrm{H}_{2} \mathrm{O}$ defect site. Using the arsenic species as the proton source did not make the reaction free energies more favourable. The displaced $\mathrm{OH}^{-}$species is protonated by a solvated proton.

\begin{tabular}{lll}
\hline Species & Binding Site & Reaction free energy $(\mathbf{k c a l} / \mathbf{m o l})$ \\
\hline $\mathrm{H}_{3} \mathbf{A s O}_{4}$ & Pristine UiO-66 & +33.0 \\
$\mathbf{H}_{2} \mathrm{AsO}_{4}{ }^{-}$ & Pristine UiO-66 & +22.7 \\
$\mathrm{H}_{2} \mathrm{AsO}_{4}{ }^{-}$ & {$[\mathrm{UiO}-66]-\mathrm{OH}-\mathrm{H}_{2} \mathrm{O}$} & +12.9 \\
$\mathbf{H A s O}_{4}{ }^{2-}$ & Pristine UiO-66 & +18.4 \\
\hline
\end{tabular}

The puzzling instability of the $\mu 3-\mathrm{OH}$ displacement adsorption mode relative to the similar tridentate mode (see main text for further discussion) can be partially attributed to the significant distortions induced in the structure of the $\mathrm{As}(\mathrm{V})$ species upon adsorption. The relevant bond lengths and reaction free energies are presented in Table S3 with bond labels in Fig. S3, along with the bond lengths for the bound arsenic and relevant binding energies. The As-O bond (bond $\mathrm{D}$ ) is significantly stretched for the $\mu 3-\mathrm{OH}$ displacement adsorption mode (bond elongation of $0.07 \AA$ for $\mathrm{H}_{3} \mathrm{AsO}_{4}, 0.04 \AA$ for $\mathrm{H}_{2} \mathrm{AsO}_{4}{ }^{-}$and $0.29 \AA$ for $\mathrm{HAsO}_{4}{ }^{2-}$ ); this extreme elongation is not present for the tridentate adsorption mode $(0.07 \AA$ at most). There is also some distortion of the UiO-66 node itself as indicated by stretching of the $\mathrm{Zr}-\mathrm{O}$ bonds (bonds (A)-(C), bond elongation of up to $0.25 \AA$ for the $\mu 3-\mathrm{OH}$ displacement adsorption mode). While the distortion of both UiO-66 and the arsenic species contributes to the instability of the $\mu 3-\mathrm{OH}$ displacement mode, other factors can also have a significant effect upon stability. $\mathrm{HAsO}_{4}{ }^{2-}$ has the most distorted arsenic structure for both adsorption modes but has the most favourable reaction free energy for adsorption; this is due to the driving force in our model to stabilize highly charged species. Additionally, the tridentate adsorption mode is destabilized for $\mathrm{H}_{3} \mathrm{AsO}_{4}$ and $\mathrm{H}_{2} \mathrm{AsO}_{4}{ }^{-}$due to protons being present on anchoring oxygens (see discussion in the main text). The stabilizing effect of saturating multiple charged oxygens in addition to having no protons on anchoring oxygens causes the tridentate adsorption mode for $\mathrm{HAsO}_{4}{ }^{2-}$ to be highly favourable. However, this stabilizing effect is not present for the $\mu 3-\mathrm{OH}$ displacement adsorption mode and due to the destabilizing effect of bond distortion, all reactions involving this adsorption mode are unfavourable. 
Table S3. A comparison of bond lengths involving the $\mu 3-O H$ oxygen (bonds (A)-(D), see Fig. S3) and $\mathrm{As}-\mathrm{O}$ bonds in bound $\mathrm{As}(V)$ species in their original state against the tridentate and $\mu 3-\mathrm{OH}$ adsorption modes for $\mathrm{H}_{3} \mathrm{AsO}_{4}, \mathrm{H}_{2} \mathrm{AsO}_{4}$ and $\mathrm{HAsO}_{4}^{2-}$. Bond lengths were measured in the gas phase structures, and distances are reported in Angstroms.

\begin{tabular}{|c|c|c|c|c|}
\hline & & $\begin{array}{l}\text { molecule / } \\
\text { Jio-66 }\end{array}$ & Tridentate & $\begin{array}{l}\mu 3-O H \text { displacement } \\
\text { on pristine UiO-66 }\end{array}$ \\
\hline \multirow[t]{8}{*}{$\mathrm{H}_{3} \mathrm{AsO}_{4}$} & $\mathrm{Zr}-\mathrm{O}(\mathrm{A})$ & 2.24 & 2.28 & 2.43 \\
\hline & $\mathrm{Zr}-\mathrm{O}(\mathrm{B})$ & 2.24 & 2.36 & 2.49 \\
\hline & $\mathrm{Zr}-\mathrm{O}(\mathrm{C})$ & 2.24 & 2.38 & 2.49 \\
\hline & As-O (D) & 1.64 & 1.68 & 1.71 \\
\hline & As-OH & 1.73 & 1.77 & 1.70 \\
\hline & As-OH & 1.73 & 1.76 & 1.70 \\
\hline & As-OH & 1.70 & 1.70 & 1.70 \\
\hline & ree energy & & +41.7 & +33.0 \\
\hline \multirow[t]{8}{*}{$\mathrm{H}_{2} \mathrm{AsO}_{4}^{-}$} & $\mathrm{Zr}-\mathrm{O}(\mathrm{A})$ & 2.24 & 2.38 & 2.40 \\
\hline & $\mathrm{Zr}-\mathrm{O}(\mathrm{B})$ & 2.24 & 2.30 & 2.41 \\
\hline & $\mathrm{Zr}-\mathrm{O}(\mathrm{C})$ & 2.24 & 2.44 & 2.41 \\
\hline & As-O (D) & 1.66 & 1.69 & 1.70 \\
\hline & As-O & 1.63 & 1.63 & 1.61 \\
\hline & As-OH & 1.75 & 1.77 & 1.74 \\
\hline & As-OH & 1.79 & 1.70 & 1.73 \\
\hline & \multicolumn{2}{|c|}{ Reaction free energy $(\mathrm{kcal} / \mathrm{mol})$} & -1.3 & +22.7 \\
\hline \multirow[t]{8}{*}{$\mathrm{HAsO}_{4}{ }^{2-}$} & $\mathrm{Zr}-\mathrm{O}(\mathrm{A})$ & 2.24 & 2.30 & 2.31 \\
\hline & $\mathrm{Zr}-\mathrm{O}(\mathrm{B})$ & 2.24 & 2.30 & 2.29 \\
\hline & $\mathrm{Zr}-\mathrm{O}(\mathrm{C})$ & 2.24 & 2.37 & 2.36 \\
\hline & As-O (D) & 1.67 & 1.73 & 1.96 \\
\hline & As-O & 1.66 & 1.65 & 1.65 \\
\hline & As-O & 1.67 & 1.66 & 1.62 \\
\hline & As-OH & 1.87 & 1.72 & 1.76 \\
\hline & \multicolumn{2}{|c|}{ Reaction free energy $(\mathrm{kcal} / \mathrm{mol})$} & -40.3 & +18.4 \\
\hline
\end{tabular}




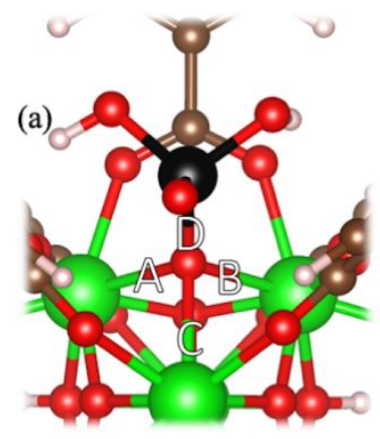

(b)

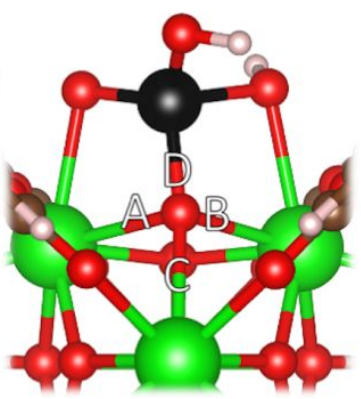

Figure S3. The accompanying figure to Table S3 indicating the bond lengths labelled (A)-(D) for the (a) $\mu 3-\mathrm{OH}$ displacement mode and (b) tridentate adsorption mode. Note that bond (C) is from the $\mathrm{Zr}$ to the $\mu 3-\mathrm{OH}$ oxygen, as opposed to the $\mu 3-\mathrm{O}$ oxygen.

\section{Steric considerations for $\mathrm{As}(\mathrm{V})$ distribution in UiO-66 pores and adsorption on neighbouring defect sites}

It is important to estimate how many As(V) molecules are able to fit within each pore in order to assess the ability of these molecules to diffuse through UiO-66 and the feasibility of the double monodentate adsorption mode. UiO-66 possesses tetrahedral pores ( $8 \AA$ approximate diameter) and octahedral pores ( $11 \AA$ approximate diameter) with access through trigonal windows (of side length $6 \AA) .{ }^{12-14}$ Using the diameter of the pores and approximating them as spheres, we can estimate the volume of both the trigonal pore $\left(\sim 270 \AA^{3}\right)$ and the octahedral pore $\left(\sim 700 \AA^{3}\right)$. The volume of $\mathrm{H}_{2} \mathrm{AsO}_{4}{ }^{-}$is estimated to be $100 \pm 5 \AA^{3}$ according to previous studies. ${ }^{15-17}$ From these approximate data, we can conclude that two $\mathrm{As}(\mathrm{V})$ molecules can fit in a tetrahedral pore and six can fit in an octahedral pore. This should be considered an upper bound given that water molecules and counterions will also be present. This estimate suggests that As(V) molecules are able to diffuse through the pores and several molecules may be present in the vicinity of the [UiO-66]$\mathrm{OH}^{-} / \mathrm{H}_{2} \mathrm{O}$ defect sites thus making the double monodentate binding mode feasible. Molecular dynamics simulations are better suited to investigate these aspects and future research efforts will be devoted to these.

The [UiO-66]-OH $-/ \mathrm{H}_{2} \mathrm{O}$ defect site results from a missing BDC linker connecting two metal oxide nodes. Hence, in the true periodic structure we would expect two neighbouring defect sites on the two metal nodes originally connected by the missing linker. As(V) adsorption in the double monodentate binding mode on both of these neighbouring defects sites would obviously be beneficial for adsorption performance. We estimated the feasibility of this adsorption configuration by visually superimposing two double monodentate binding mode structures modelled with our cluster model of the metal oxide node over the pristine periodic structure while maintaining scale and appropriate distance between both nodes (Fig. S4). We found that it is possible for four As(V) species to co-adsorb across opposing defect sites without steric hindrance. The distance across the BDC linker is approximately $11 \AA$, while the double monodentate binding mode extends $4.5 \AA$ into the pore. This suggests that it may be possible for the four As(V) species 
to form stabilizing intermolecular hydrogen bonds. However, charge build-up and electrostatic repulsion could prevent co-adsorption of four highly negatively charged species such as $\mathrm{HAsO}_{4}{ }^{2-}$. This could further explain the heightened adsorption performance in acidic conditions where the As $(V)$ species are less negatively charged. Additionally, larger pores could facilitate this binding mode and reduce electrostatic repulsion thus leading to enhanced adsorption in agreement with experimental reports showing enhanced performance when using UiO-67. ${ }^{4}$

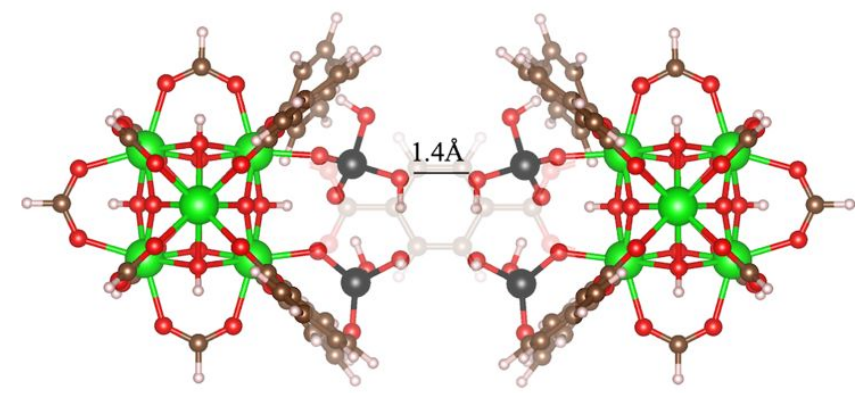

Figure S4. Approximate adsorption configuration of four $\mathrm{H}_{2} \mathrm{AsO}_{4} \mathrm{O}^{-}$species bound in double monodentate binding mode at the defect sites present on two neighbouring UiO-66 nodes originally connected by a displaced 1,4-benzenedicarboxylic acid (BDC) linker. To obtain this approximate configuration two optimised double monodentate binding mode structures modelled using our cluster model of the metal oxide node are overlaid on the periodic UiO-66 structure; no further optimisations were conducted. The position of the BDC linker is partially transparent in the background to indicate that the two UiO-66 nodes are placed at a correct distance based on the periodic structure.

\section{Co-adsorption of different pairs of $\mathrm{As}(\mathrm{V})$ species in double monodentate adsorption mode}

Given the superior stability of the double monodentate adsorption mode, we investigated the possibility of different pairs of $\mathrm{As}(\mathrm{V})$ species co-adsorbing in this adsorption mode in order to determine the most favourable combination in both acidic and neutral conditions (Fig. S5). In acidic conditions, the preferred adsorbed pair is the neutral $\mathrm{H}_{3} \mathrm{AsO}_{4} / \mathrm{H}_{2} \mathrm{AsO}_{4}{ }^{-}$complex $(\Delta \mathrm{G}=-31.5$ $\mathrm{kcal} / \mathrm{mol}$ for $\mathrm{H}_{3} \mathrm{AsO}_{4} / \mathrm{H}_{2} \mathrm{AsO}_{4}{ }^{-}$initial species, Fig. S5). For species present at less acidic $\mathrm{pH}$ (i.e., for all initial $\mathrm{As}(\mathrm{V})$ pairs except $\left.\mathrm{H}_{3} \mathrm{AsO}_{4} / \mathrm{H}_{3} \mathrm{AsO}_{4}\right)$, the preferred proton source for the protonation of the displaced hydroxide is solvated protons as opposed to $\mathrm{As}(\mathrm{V})$ (in agreement with Figs. 3 and 4). We observe that the reaction free energy for adsorption increases for the pairs adsorbing without deprotonation in the order $\mathrm{H}_{3} \mathrm{AsO}_{4} / \mathrm{H}_{3} \mathrm{AsO}_{4}<\mathrm{H}_{3} \mathrm{AsO}_{4} / \mathrm{H}_{2} \mathrm{AsO}_{4}{ }^{-}<\mathrm{H}_{2} \mathrm{AsO}_{4}-\mathrm{H}_{2} \mathrm{AsO}_{4}{ }^{-}<\mathrm{H}_{2} \mathrm{AsO}_{4}{ }^{-}$ $/ \mathrm{HAsO}_{4}{ }^{2-}<\mathrm{HAsO}_{4}{ }^{2-} / \mathrm{HAsO}_{4}{ }^{2-}$. All $\mathrm{As}(\mathrm{V})$ adsorbed double monodentate combinations form the same number of hydrogen bonds with each other and the $\mu 3-\mathrm{OH}$ site so the more favourable reaction free energies for initial binding pairs that involve $\mathrm{HAsO}_{4}{ }^{2-}(\Delta \mathrm{G}=-45.5 \mathrm{kcal} / \mathrm{mol}$ for $\mathrm{HAsO}_{4}{ }^{2-} / \mathrm{HAsO}_{4}{ }^{2-}$ initial species) relative to binding pairs that involve $\mathrm{H}_{3} \mathrm{AsO}_{4}$ can be attributed solely to the highly stabilizing effect of binding charged species. This finding would suggest a 
larger driving force for double monodentate to occur at less acidic $\mathrm{pH}$ and thus potentially higher adsorption performance. As thoroughly discussed in the main text, such increases in reaction free energy are likely biased by poor stabilization of negatively charged species in our model. Furthermore, the adsorption of more negatively charged species adsorbing will lead to charge build up on the UiO-66 surface and eventually cause electrostatic repulsion that would prevent further adsorption. These considerations might explain why low $\mathrm{pH}$ still provides better adsorption performance in experimental conditions.

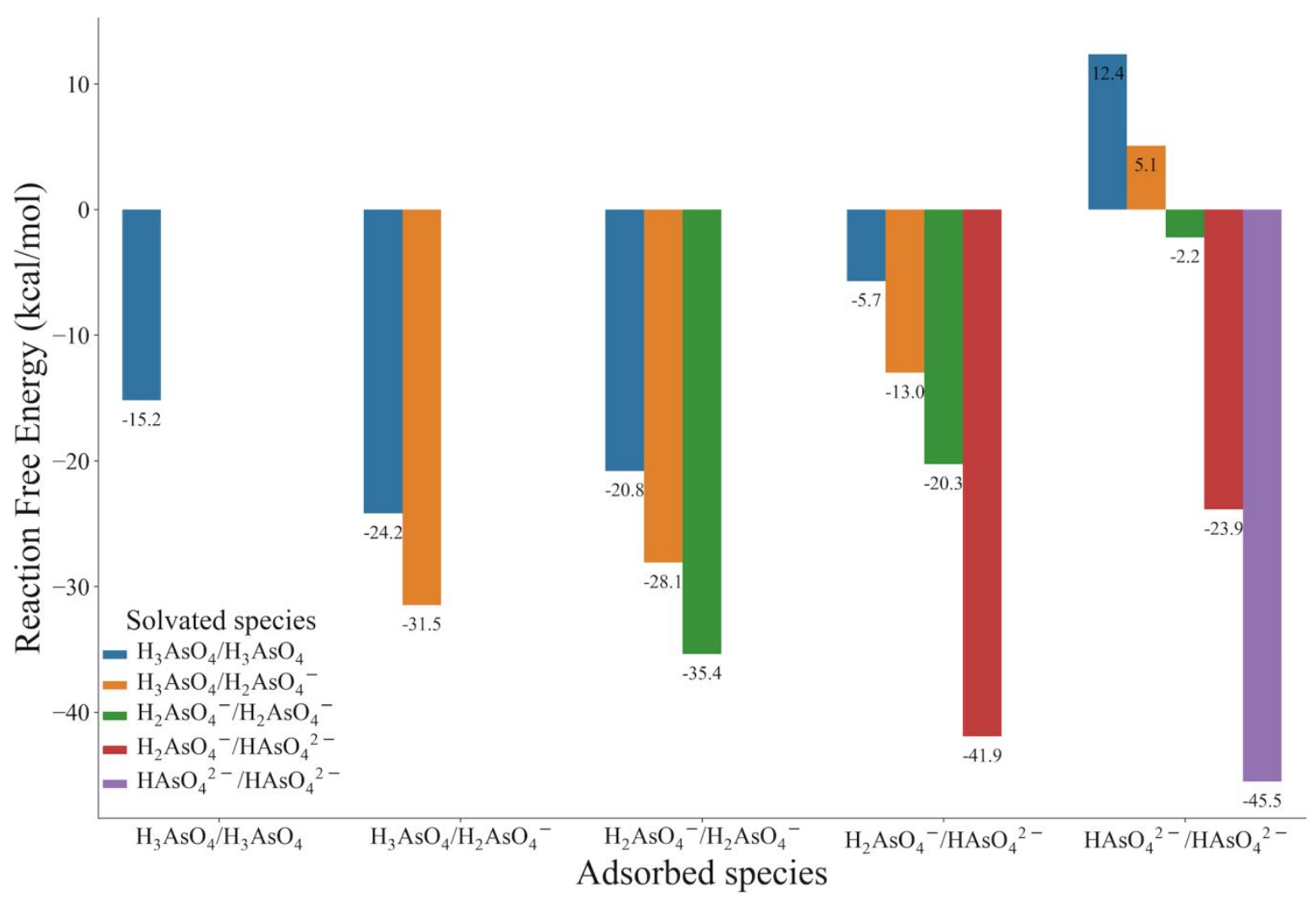

Figure S5. A comparison of the double monodentate adsorption mode across all permutations of initial species and adsorbed species. Only acidic and neutral conditions were analysed, as the double monodentate adsorption mode is unstable for AsO43- due to electrostatic repulsion. Reaction free energies are calculated relative to the [UiO-66]-OH- $/ \mathrm{H}_{2} \mathrm{O}$ defect site. The reaction studied is [UiO-66]-OH- $/ \mathrm{H}_{2} \mathrm{O}+\mathrm{H}_{u} \mathrm{AsO}_{4}{ }^{u-3}+\mathrm{H}_{v} \mathrm{AsO}_{4}{ }^{v-3}+w^{+} \rightarrow[\mathrm{Ui}-\mathrm{O} 66]-\mathrm{H}_{x} \mathrm{AsO} \mathrm{O}^{x-4} / \mathrm{H}_{y} \mathrm{AsO} \mathrm{O}^{\mathrm{y}-4}$ $+2 \mathrm{H}_{2} \mathrm{O}+z \mathrm{H}^{+}(u, v, x, y=1,2,3$ depending on initial and adsorbed species, $y=0,1,2,3$ where $y=0$ if the proton source is from $A s(V)$ and $y=1$ if the proton source is from a solvated proton, and $z=0,1,2,3$, where $z=(u+v)-(x+y)-1$. For reactions not involving $A s(V)$ deprotonation, the displaced $\mathrm{OH}^{-}$is protonated by a solvated proton.

\section{References}

(1) Keith, J. A.; Carter, E. A. Quantum Chemical Benchmarking, Validation, and Prediction of Acidity Constants for Substituted Pyridinium Ions and Pyridinyl Radicals. J. Chem. Theory Comput. 2012, 8 (9), 3187-3206. 
(2) Torres, J.; Santos, P.; Ferrari, C.; Kremer, C.; Kremer, E. Solution Chemistry of Arsenic Anions in the Presence of Metal Cations. J. Solution Chem. 2017, 46 (12), 2231-2247.

(3) Wang, C.; Liu, X.; Chen, J. P.; Li, K. Superior Removal of Arsenic from Water with Zirconium Metal-Organic Framework UiO-66. Sci. Rep. 2015, 5, 16613.

(4) Audu, C. O.; Nguyen, H. G. T.; Chang, C. Y.; Katz, M. J.; Mao, L.; Farha, O. K.; Hupp, J. T.; Nguyen, S. T. The Dual Capture of AsV and AsIII by UiO-66 and Analogues. Chem. Sci. 2016, 7 (10), 6492-6498.

(5) Xu, R.; Ji, Q.; Zhao, P.; Jian, M.; Xiang, C.; Hu, C.; Zhang, G.; Tang, C.; Liu, R.; Zhang, X.; Qu, J. Hierarchically Porous UiO-66 with Tunable Mesopores and Oxygen Vacancies for Enhanced Arsenic Removal. J. Mater. Chem. A 2020, 8 (16), 7870-7879.

(6) Kesharwani, M. K.; Brauer, B.; Martin, J. M. L. Frequency and Zero-Point Vibrational Energy Scale Factors for Double-Hybrid Density Functionals (and Other Selected Methods): Can Anharmonic Force Fields Be Avoided? J. Phys. Chem. A 2015, 119 (9), 1701-1714.

(7) Valenzano, L.; Civalleri, B.; Chavan, S.; Bordiga, S.; Nilsen, M. H.; Jakobsen, S.; Lillerud, K. P.; Lamberti, C. Disclosing the Complex Structure of UiO-66 Metal Organic Framework: A Synergic Combination of Experiment and Theory. Chem. Mater. 2011, 23 (7), 17001718.

(8) Shearer, G. C.; Chavan, S.; Ethiraj, J.; Vitillo, J. G.; Svelle, S.; Olsbye, U.; Lamberti, C.; Bordiga, S.; Lillerud, K. P. Tuned to Perfection: Ironing out the Defects in Metal-Organic Framework UiO-66. Chem. Mater. 2014, 26 (14), 4068-4071.

(9) Cui, H.; Li, Q.; Gao, S.; Shang, J. K. Strong Adsorption of Arsenic Species by Amorphous Zirconium Oxide Nanoparticles. J. Ind. Eng. Chem. 2012, 18 (4), 1418-1427.

(10) Hunter, K. M.; Shakib, F. A.; Paesani, F. Disentangling Coupling Effects in the Infrared Spectra of Liquid Water. J. Phys. Chem. B 2018, 122 (47), 10754-10761.

(11) Assaad, N.; Sabeh, G.; Hmadeh, M. Defect Control in Zr-Based Metal-Organic Framework Nanoparticles for Arsenic Removal from Water. ACS Appl. Nano Mater. 2020, 3 (9), 89979008.

(12) Cavka, J. H.; Jakobsen, S.; Olsbye, U.; Guillou, N.; Lamberti, C.; Bordiga, S.; Lillerud, K. P. A New Zirconium Inorganic Building Brick Forming Metal Organic Frameworks with Exceptional Stability. J. Am. Chem. Soc. 2008, 130 (42), 13850-13851.

(13) Biswas, S.; Zhang, J.; Li, Z.; Liu, Y. Y.; Grzywa, M.; Sun, L.; Volkmer, D.; Van Der Voort, P. Enhanced Selectivity of $\mathrm{CO} 2$ over $\mathrm{CH} 4$ in Sulphonate-, Carboxylate- and IodoFunctionalized UiO-66 Frameworks. Dalt. Trans. 2013, 42 (13), 4730-4737.

(14) Chavan, S.; Vitillo, J. G.; Gianolio, D.; Zavorotynska, O.; Civalleri, B.; Jakobsen, S.; Nilsen, M. H.; Valenzano, L.; Lamberti, C.; Lillerud, K. P.; Bordiga, S. H2 Storage in Isostructural UiO-67 and UiO-66 MOFs. Phys. Chem. Chem. Phys. 2012, 14 (5), 16141626. 
(15) Parsons, D. F.; Ninham, B. W. Ab Initio Molar Volumes and Gaussian Radii. J. Phys. Chem. $A$ 2009, 113 (6), 1141-1150.

(16) Tanaka, M.; Takahashi, Y.; Yamaguchi, N.; Kim, K. W.; Zheng, G.; Sakamitsu, M. The Difference of Diffusion Coefficients in Water for Arsenic Compounds at Various PH and Its Dominant Factors Implied by Molecular Simulations. Geochim. Cosmochim. Acta 2013, $105,360-371$.

(17) Pincus, L. N.; Rudel, H. E.; Petrović, P. V.; Gupta, S.; Westerhoff, P.; Muhich, C. L.; Zimmerman, J. B. Exploring the Mechanisms of Selectivity for Environmentally Significant Oxo-Anion Removal during Water Treatment: A Review of Common Competing OxoAnions and Tools for Quantifying Selective Adsorption. Environ. Sci. Technol. 2020, 54 (16), 9769-9790.

\section{Cartesian coordinates of structures used in this work}

The Cartesian coordinates of all relevant structures (including cluster models and free species in solution) are provided in the accompanying .zip file named "Cox_CossichGalicia_Lessio_2020_Coordinates.zip". 